How do men in the United Kingdom decide to dispose of banked sperm following cancer treatment?

6

7

8

9

Pacey, A.A. ${ }^{*}{ }^{1}$ Merrick, H. ${ }^{2}$, Arden-Close, E. ${ }^{2}$, Morris, $K^{1}$., Tomlinson, M.J. ${ }^{3}$, Rowe, R. ${ }^{2}$, \& Eiser, C². $^{2}$

12

13

${ }^{1}$ Academic Unit of Reproductive and Developmental Medicine, Department of Human Metabolism, 16

${ }^{3}$ Fertility Unit, Nottingham University Hospital, East Block, B Floor, Derby Road, Nottingham, NG7 2UH, UK.

*Address for correspondence (A.Pacey@Sheffield.ac.uk)

26

Running title: Disposal of banked sperm by cancer survivors

28

29

Key words: Cancer, Semen cryopreservation, Male infertility, Psychology 
33 Current policy in the UK recommends that men bank sperm prior to cancer treatment, but very few 34 return to use it for reproductive purposes or agree to elective disposal even when their fertility recovers 35 and their families are complete. We assessed the demographic, medical and psychological variables that influence the decision to dispose by contacting men $(n=499)$ who banked sperm more than five years previously and asked them to complete questionnaires about their views on sperm banking, fertility and disposal. From 193 responses (38.7\% response rate) 19 men (9.8\%) requested disposal within four months of completing the questionnaire. Compared with men who wanted their sperm to remain in storage, they were significantly more confident that their fertility had recovered $(O R=1.78$, $95 \% \mathrm{Cl}=1.05-3.03, p=0.034$ ), saw fertility monitoring (semen analysis) as less important (OR $=0.61$, $95 \% \mathrm{Cl}=0.39-0.94, p=0.026)$, held more positive attitudes to disposal $(\mathrm{OR}=5.71,95 \% \mathrm{Cl}=2.89$ -

$4311.27, p<0.001)$, were more likely to have experienced adverse treatment side effects $(\mathrm{OR}=4.37, \mathrm{Cl}=$ 1.61-11.85, $p=0.004)$ and had less desire for children in the future $(\mathrm{OR}=0.41,95 \% \mathrm{Cl}=0.26-0.64$, $p<.001)$. Information about men's reasons to dispose of banked sperm may be helpful in devising new strategies to encourage men to engage with sperm banking clinics and make timely decisions about the fate of their samples.

48 
52 Sperm banking is routinely recommended for post-pubertal males prior to anti-neoplastic treatment 53 (National Collaborating Centre for Women's and Children's Health, 2004; European Society for Human 54 Reproduction and Embryology, 2004; Lee et al., 2006; Royal College of Physicians, 2007; National 55 Institute for Health and Clinical Excellence, 2013; Loren et al., 2013). In the UK, sperm may be stored 56 for up to 55 years (Human Fertilisation and Embryology Authority, 2009) and audits and reviews are needed to comply with legislative requirements. The low rates of use (Lass et al., 2001) or disposal (Hallak et al., 1998) mean that sperm banks are increasing in size and therefore compliance with these legal requirements is becoming time-consuming and expensive. Therefore, an understanding of how men make decisions about disposal is needed to contribute to more appropriate and cost effective use of sperm banks.

62

63 Previous work suggests that disposal rates range from 8.7\% (Meseguer et al., 2006) to 23.8\% 64 (Blackhall et al., 2002). Across nine studies, most disposals followed the man's death and few 'elective disposals' were reported (see Pacey and Eiser, 2011). Hallak et al., (1998) reported that most men who chose to dispose did so because their fertility improved. In an interview study (Eiser et al, 2011), men described complex and unresolved views about banked sperm. Many saw banked sperm as psychological protection against fertility decline if they relapsed, although others saw psychological benefits to disposal in that it allowed them to put the cancer experience behind them and 'move on'.

In a cohort of men who banked sperm at least five years previously (Pacey et al., 2012), we reported that the men's experience of adverse side effects, their initial experience of banking sperm and attitudes to disposal contributed to whether or not they attended for fertility monitoring. Using the same cohort of men, we now report the (i) frequency of elective disposal of banked sperm, and (ii) demographic, medical and psychological variables contributing towards this decision. 
Method

\section{Recruitment and Measures}

78 We contacted a cohort of 499 men between April 2008 and December 2010 who had banked sperm more than five years previously, prior to gonadotoxic treatment for cancer as described in Pacey et al.,

80 (2012) and approved the by Trent Research Ethics Committee (Ref: 07/H0405/61). Briefly, the eligibility 81 criteria included age (18-55 years), no known mental health problems, and sufficient English language 82 ability to provide written informed consent and complete questionnaires. The men were recruited from 83 sperm banks in Sheffield Teaching Hospitals NHS Foundation Trust (Jessop Wing, Tree Root Walk, 84 Sheffield) and Nottingham University Hospitals NHS Trust (Queen's Medical Centre, Derby Road, 85 Nottingham). In both hospitals, the subjects were written to and regularly informed about the need to 86 attend follow-up and check any changes to their fertility and were given the opportunity to update their 87 consent. In both centres, long-term storage was free of charge with the cost being covered by the 88 National Health Service.

$89 \quad$ The men completed specially developed questionnaires to determine: (a) Experience of banking 90 sperm (e.g., "I had the right amount of support from others in making this choice," and "I am pleased I 91 decided to bank"); (b) Information about Fertility (number of samples they recalled banking, quality of banked samples ("did not have any sperm to bank" , "good enough for fertility treatment" or "don't know"), usefulness of knowing the quality of banked sperm (rated on a five point scale from "definitely very useful" to "definitely not very useful"), and current use of contraception (rely on partner, trying for a child, not in a relationship, fertility too low)); (c) Views about follow up (e.g., "I don't want to know if my fertility has recovered or not", "I am certain my fertility has already or will recover"); d) Attitudes to disposal (e.g., "If tests show my fertility has recovered, I would agree to disposal"); and (e) Children and Parenting (e.g., "How much has your experience of cancer affected your wish to have children in future?," "I worry that children born from banked sperm will have health problems"). Current late effects and perceived vulnerability were assessed using a standardized measure (Absolom et al., 2006). Responses were made on 5-point Likert rating scales with appropriate end-points or multiple choice options.

Relevant medical and demographic information was extracted from medical records held by the 103 sperm bank.

Analysis

106 All continuous variables were standardised prior to analysis. We used independent samples t-tests and 107 chi-square analyses to examine differences on all variables between those who decided to dispose of 108 their samples and those who wanted them to remain in storage. 
111 A total of 193 men returned completed questionnaires (38.7\% response rate) as summarized in Figure 1.

112 Of those men who responded, samples had been banked for $9.18 \pm 3.70$ years (range $=4.94-26.21$ ) and 113 their current age was $35.08 \pm 7.08$ years (range $=21.58-54.34)$ (mean \pm SD). One third $(35.7 \%)$ had 114 never attended for semen analysis [as reported in Pacey et al. 2012] and in addition, over the study 115 period, 34 men (17.6\%) disposed of their sample. However, the men joined the study over an extended 116 period of time and the duration of follow-up differed between patients (range 4 - 43 months). We 117 therefore modelled the men's decisions about banking to meet minimum follow-up possible (4 months 118 after completing questionnaires) and nineteen men (9.8\%) requested disposal within this 4-month 119 window.

121 Demographic, medical and psychological variables predicting the decision to dispose of banked sperm

122 Preliminary analyses of the information in medical records held in the sperm bank, indicated that there 123 were no significant differences between men who agreed to disposal and those who did not, in terms of 124 diagnosis, treatment, co-morbid conditions, participation in a clinical trial, relapse, reported late effects, or 125 the number of ejaculates banked, the number of years that banked sperm was held in storage, pre-freeze 126 motile concentration of the first banked sample, or number of attendances for fertility monitoring since 127 banking. Importantly, there was no difference in post-treatment motile concentration between the 128 disposers (mean $=15.87 \pm 14.75 \times 10^{6}$ per $\mathrm{ml}$ ) and those who continued storage (mean $=17.72 \pm 26.52$ $129 \times 10^{6}$ per $\mathrm{ml}$ ). However, disposers were more likely to have experienced adverse treatment side-effects $130 \quad(\mathrm{OR}=4.37, \mathrm{Cl}=1.61-11.85, \mathrm{p}=0.004)$.

132 Men who agreed to disposal were significantly older (mean \pm SD: $38.81 \pm 6.13$ versus $34.64 \pm 7.07$ ) than 133 those who retained the sperm in storage (OR for 1 year increase=1.09, 95\% Cl=1.02-1.17, $p=0.017$ ), 134 more likely to have left full-time education under 18 years of age $(\mathrm{OR}=3.23,95 \% \mathrm{Cl}=1.03-10.11$, $135 \mathrm{p}=0.045)$ and to live with a partner $(\mathrm{OR}=4.47,95 \% \mathrm{Cl}=1.00-20.01, \mathrm{p}=0.050)$ and had significantly more 136 children $(1.42 \pm 1.30$ versus $0.75 \pm 1.17)$ than men who did not agree to disposal (OR for an additional 137 child=1.45, 95\% Cl=1.05-2.01, $\mathrm{p}=0.019$ ). There were no differences in employment (working or not; $138 \mathrm{OR}=0.99, \mathrm{Cl}=0.31-3.15, \mathrm{p}=0.980$ ) or distance from home to the sperm bank (OR for 1 mile 139 increase $=0.99, \mathrm{Cl}=0.96-1.01, \mathrm{p}=0.165)$.

141 The men who requested disposal were significantly more confident that their fertility had recovered $142(\mathrm{OR}=1.78,95 \% \mathrm{Cl}=1.05-3.03, \mathrm{p}=0.034)$, saw fertility monitoring (semen analysis) as less important $143(\mathrm{OR}=0.61,95 \% \mathrm{Cl}=0.39-0.94, \mathrm{p}=0.026)$, held more positive attitudes to disposal $(\mathrm{OR}=5.71,95 \%$ 
$144 \mathrm{Cl}=2.89-11.27, \mathrm{p}<0.001)$ and had less desire for children in the future $(\mathrm{OR}=0.41,95 \% \mathrm{Cl}=0.26-0.64$, $145 p<0.001)$ than men who wanted their sperm to remain in storage.

\section{Discussion}

148 This study was initiated in response to an urgent practical question regarding extended and unnecessary

149 storage. Our data support previous findings that disposal rates are low: of 193 men, 19 (9.8\%) requested

150 elective disposal of banked samples within four months of completing questionnaires, lower than 151 previously reported (18.6\% across 9 studies summarised in Pacey and Eiser, 2011). However, previous

152 studies were usually longer-term audits where disposal rates are reported over a substantially longer 153 period of time (e.g. 22 years: Kelleher et al., 2001). Our disposal rate may well be higher in the longer154 term, and indeed over the course of the study we found that 34 men (17.6\%) requested disposal. 155 However, the shorter follow-up is more meaningful in order relate decisions about disposal to 156 questionnaire responses.

159 Given the low rates of disposal, we attempted to identify variables that distinguished between those who 160 did, and did not, dispose of samples in the study period. These included being older, leaving full-time education before reaching 18 years of age, having more children and living with a partner, suggesting 162 some relationship between the decision to dispose and family structure. Men who leave full-time 163 education under the age of 18 generally start families sooner than those who enter a period of further 164 education and training (Eggebeen, 2002). Other variables significantly associated with disposal included 165 whether the treatment side-effects were recorded in medical notes, and self-rated confidence in fertility 166 recovery, lower importance of fertility monitoring (semen analysis), desire for children in the future, and 167 attitudes to disposal. Hallak et al., (1998) also found that the decision about disposal was not related to 168 age, number of specimens stored and time between diagnosis and treatment but did depend on the type 169 of treatment. Both Hallak et al. (1998) and Meseguer et al. (2006) concluded that aside from death, most 170 reasons for elective disposal included recovered fertility and no desire for further children. However, in 171 the context of our study it is interesting to speculate if our questionnaire itself may have acted as an 172 intervention by prompting men to consider disposal when they otherwise would not have done so. This 173 effect has been noted before in the context of blood donation (Godin et al., 2008) where the receipt and 174 completion of a questionnaire among registered donors increased their participation rates in comparison 175 to a control group. This is an area for further investigation.

176 Limitations of the study include the poor response rate (38.7\%) but this may reflect the general difficulties 177 encountered when trying to recruit men to research fertility (Stewart et al., 2009) or other fertility related 
178 follow-up (Chawla et al., 2004). We have only limited information about non-responders, although we have recently published a summary of interviews with six men who had held their sperm in storage for almost 10 years and who had never returned to the sperm bank (Eiser et al., 2014). This suggests that men's reasons for not responding are a complex interplay between past, present and future perspectives including fears of being told fertility has not recovered and being pressured to dispose of banked sperm. Responses to questionnaires relied on recall of events many years previously and may reflect some recall bias. Our results are limited to views of men following cancer treatment and may differ for those who bank sperm for other reasons. Our decision to focus on men who bank sperm following cancer treatment were justified because referrals to sperm banks following cancer diagnosis are more prevalent than for other causes (Pacey, 2009). We investigated a finite range of variables that might contribute to men's decisions and other variables may be worthy of investigation in the future. For example, decisions may well be influenced by cost where charges are collected for storage and concerns about the possible teratogenic nature of the treatment which could affect the health of any children born. For some, this may be a justifiable concern, but for others sensitive counselling may be needed to ensure that rational decisions are made.

Information and counselling may assist men in making timely decisions (Pacey and Eiser, 2011). On-line information currently available about sperm banking typically requires more sophisticated reading skills than generally held the public (Merrick et al., 2012). Health professionals should provide easy to understand information throughout cancer treatment, and not just on diagnosis. Men consistently describe how they rely on medical staff and family to help them make decisions to bank when diagnosed with cancer (Pacey et al., 2013). Health Professionals need to take into account men's sources of support and the wider issues that contribute to views about disposal. We suggest that men's attitudes to disposal are underpinned by a complex series of variables concerning their experience and particularly the side effects of treatment, views about fertility, domestic arrangements, and desire for future children. In order to answer questions about the viability of sperm banks (Lass et al., 2001), it is vital to increase our understanding of why men bank sperm, their reasons for using banked samples for reproduction and the rationale for retaining samples in storage even when they do not anticipate using them in the future.

Given that banked sperm can be stored for up to 55 years in the UK (Human Fertilisation and Embryology Authority, 2009), it is important that those responsible for day-to-day management of sperm banks are aware of the complexity of these issues. Storage of sperm allows men to achieve optimal quality of life after cancer treatment but there are implications for health care resources. Men need to understand from diagnosis that sperm quality will change in the years following treatment. They should 
212 therefore, be encouraged to engage with the sperm banking service during treatment and beyond, in

213 order to make timely decisions about disposal of stored samples if they are no longer needed for assisted 214 conception.

215

\section{Acknowledgements}

217 The authors would like to thank Debbie Saxton (Sheffield) and Tracey Kohut (Nottingham) for their help

218 with the recruitment procedures. This paper was supported by funding from Cancer Research-UK to CW, AAP

219 and RR (C481/A8141). The views expressed are those of the authors.

220

221

\section{Declaration of interest}

222 The authors report no declarations of interest. The authors alone are responsible for the content and writing of the 223 paper.

224

225 
227 Absolom K, Greenfield D, Ross R, Horne B, Davies H, Glaser A, Simpson A, Waite H, Eiser C. Predictors 228 of clinic satisfaction among adult survivors of childhood cancer. Europ J Cancer 2006; 42: 1421-1427.

229

Blackhall FH, Atkinson AD, Maaya MB, Ryder WD, Horne G, Brison DR, Lieberman BA, Radford JA. Semen cryopreservation, utilisation and reproductive outcome in men treated for Hodgkin's disease. Brit J Cancer 2002; 87: 381-384.

Chawla A, Bowles, Zini A. Vasectomy follow-up: clinical significance of rare non-motile sperm in postoperative semen analysis. Urology; 64, 1212-1215.

Eiser C, Arden-Close E, Morris K, Pacey AA. The legacy of sperm banking: how fertility monitoring and disposal are linked with views of cancer treatment. Hum Reprod 2011; 26: 2791-2798.

Eiser C, Merrick H, Arden-Close E, Morris K, Rowe R, Pacey AA. Why don't some men with banked sperm respond to letters about their stored samples? Hum Fertil. Posted online on June 19 2014. Doi: 10.3109/14647273.2014.922703

European Society for Human Reproduction and Embryology. Taskforce 7: Ethical considerations for the cryopreservation of gametes and reproductive tissues for self-use. Human Reprod 2004; 19: 460-462.

Godin G, Sheeran P, Conner M, Germain M. Asking questions changes behavior: mere measurement effects on frequency of blood donation. Health Psychol 2008; 27; 179-184.

Hallak, J., Sharma, R.K., Thomas, A.J., \& Agarval, A. Why cancer patients request disposal of cryopreserved semen specimens post-therapy: a retrospective study. Fertil Steril 1998 69: 889-883.

Human Fertilisation and Embryology Authority. Code of Practice. 8th Edition. HFEA, London. 2009.

Kelleher S, Wishart SM, Liu PY, Turner L, Di Pierro I, Conway AJ, Handelsman DJ. Long-term outcomes of elective human sperm cryostorage. Hum Reprod 2001 16: 2632-2639.

Lass A, Akagbosu F, Brinsden P. Sperm banking and assisted reproduction treatment for couples following cancer treatment of the male partner. Hum Reprod 2001; 7: 370-377.

Lee SJ, Schover LR, Partridge AH, Ann H, Patrizio P, Wallace H, Hagerty K, Beck LN, Brennan LV, Oktay K. American Society of Clinical Oncology recommendations on fertility preservation in cancer patients. J Clinical Oncol, 2006; 24: 2917-2931.

Loren AW, Mangu PB, Beck LN, Brennan L, Magdalinski AJ, Partridge AH, Quinn G, Wallace WH, Oktay K. Fertility Preservation for Patients With Cancer: American Society of Clinical Oncology Clinical Practice Guideline Update. J Clin Oncol. 2013 (published on advanced access)

Merrick $\mathrm{H}$, Wright $\mathrm{E}$, Pacey $\mathrm{AA}$, Eiser $\mathrm{C}$. Finding out about sperm banking: what information is available online for men diagnosed with cancer? Hum Fertil 2012; 15: 121-128.

Meseguer M, Molina N, Garcia-Velasco JA, Remohi J, Pellicer A, Garrido N. Sperm cryopreservation in oncology patients: a 14-year follow-up study. Fertil Steril 2006; 85: 640-645. 
274 National Collaborating Centre for Women's and Children's Health. Fertility: Assessment and Treatment 275 for People with Fertility Problems. Commissioned by the National Institute for Clinical Excellence. 276 London: RCOG Press ISBN 1-900364-97-2 (February). 2004.

National Institute for Health and Clinical Excellence. Fertility - Assessment and Treatment for people with fertility problems. Nice Clinical Guideline 156. (February 2013).

Pacey AA. Referring patients for sperm banking. In Pacey AA, Tomlinson MJ (Eds), Sperm Banking Theory and Practice. 2009. Cambridge: Cambridge University Press, pp 110-128.

Pacey AA, Eiser $C$, Banking sperm is only the first of many decisions for men: What healthcare professionals and men need to know? Hum Fertil 2011; 14: 208-217.

Pacey AA, Merrick H, Arden-Close E, Morris K, Barton LC, Crook AJ, Tomlinson MJ, Wright E, Rowe R, Eiser C. Monitoring fertility (semen analysis) by cancer survivors who banked sperm prior to cancer treatment. Hum Reprod 2012; 27: 3132-3139.

Pacey AA, Merrick H, Arden-Close E, Morris K, Rowe R, Stark D, Eiser C. Implications of sperm banking for health-related quality of life up to 1 year after cancer diagnosis. British Journal of Cancer 2013; 108: 1004-1011.

Royal College of Physicians. The Effects of Cancer Treatment on Reproductive Functions. Guidance on Management. London: Royal College of Physicians.72pp. 2007.

299 factors affecting pregnancy rates in fertile men. Hum Reprod 2009; 24: 240-248. 


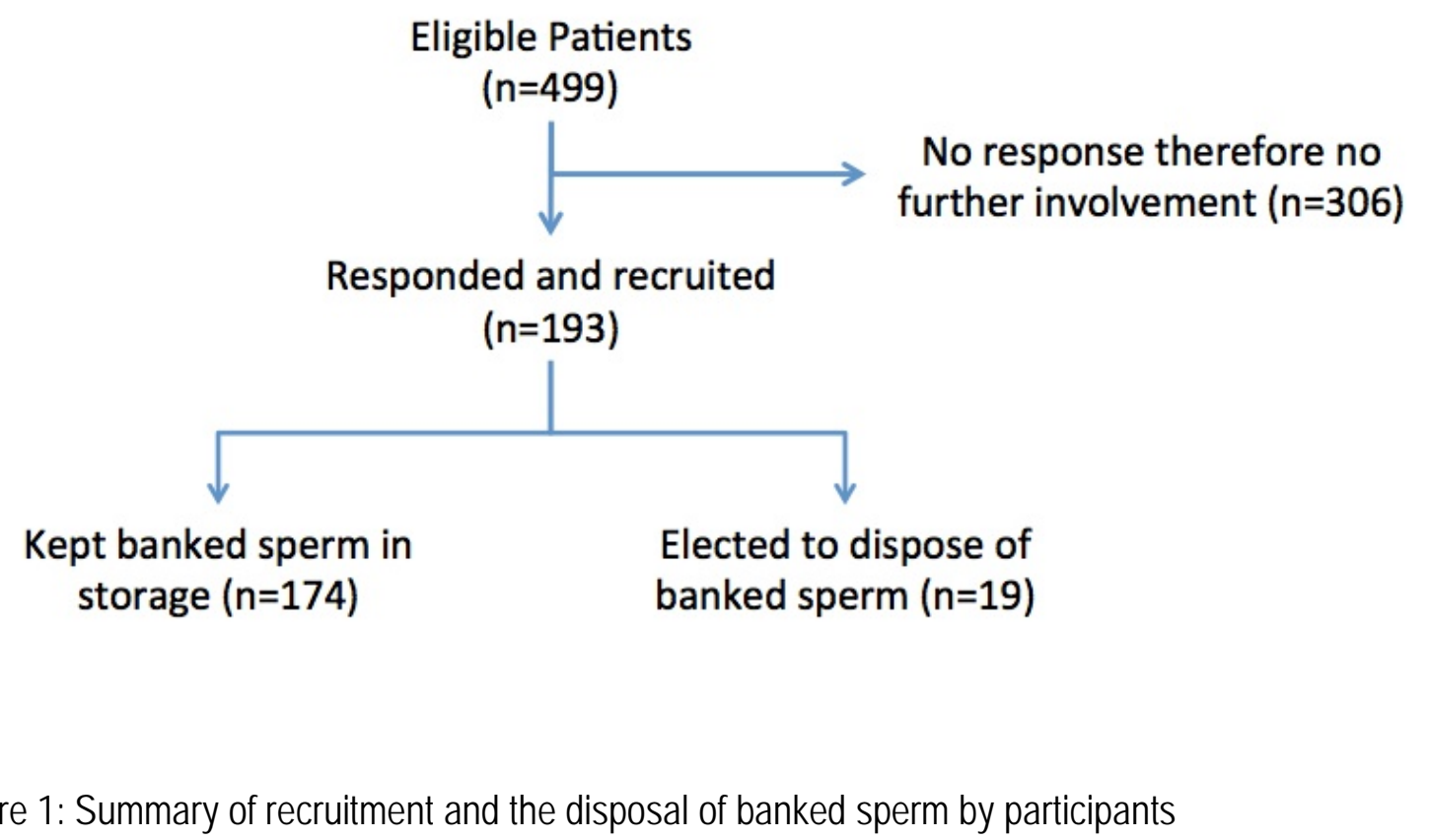

